\title{
Octahedral Non-Heme Oxo- and Non-Oxo Fe(IV) Complexes: An Experimental/Theoretical Comparison
}

John F. Berry, Eckhard Bill, Eberhard Bothe, Frank Neese, and Karl Wieghardt*

\section{Supporting Information}

Table S1. Geometric data for calculated structures of the $\left[\left(\mathrm{Me}_{3} \text { cyclam-acetate }\right) \mathrm{FeF}\right]^{n+}$ series, $n=0,1,2$ using double- $\xi$ basis sets.

\begin{tabular}{|c|c|c|c|}
\hline & $\begin{array}{l}\left(\mathrm{Me}_{3} \text { cyclam-acetate }\right) \mathrm{FeF} \\
S=2\end{array}$ & $\begin{array}{l}{\left[\left(\mathrm{Me}_{3} \text { cyclam-acetate }\right) \mathrm{FeF}\right]^{2+}} \\
S=1\end{array}$ & $\begin{array}{l}{\left[\left(\mathrm{Me}_{3} \text { cyclam-acetate }\right) \mathrm{FeF}\right]^{2+}} \\
S=2\end{array}$ \\
\hline $\mathrm{Fe}-\mathrm{F}, \AA$ & 1.911 & 1.762 & 1.763 \\
\hline $\mathrm{Fe}-\mathrm{Nav}, \AA$ & 2.262 & 2.125 & 2.222 \\
\hline $\mathrm{Fe}-\mathrm{O}, \AA$ & 2.077 & 1.799 & 1.802 \\
\hline $\mathrm{O}-\mathrm{Fe}-\mathrm{F},{ }^{\circ}$ & 172.1 & 174.0 & 171.2 \\
\hline$\Delta d\left(\mathrm{Fe}-\mathrm{N}_{4}\right), \AA^{\mathrm{a}}$ & 0.119 & 0.023 & 0.039 \\
\hline
\end{tabular}

${ }^{\mathrm{a}}$ This is the distance of the iron atom above the plane formed by the four amine nitrogen atoms 
Table S2. Calculated geometries of [( $\mathrm{Me}_{3}$ cyclam-acetate $\left.) \mathrm{FeO}\right]^{+}$using $\mathrm{SV}(\mathrm{P})$ basis sets.

\begin{tabular}{lll}
\hline & $S=1$ & $S=2$ \\
\cline { 2 - 3 } $\mathrm{Fe}=\mathrm{O}, \AA$ & 1.662 & 1.660 \\
$\mathrm{Fe}-\mathrm{N}_{\mathrm{av}}, \AA$ & 2.112 & 2.210 \\
$\mathrm{Fe}-\mathrm{O}, \AA$ & 1.943 & 1.928 \\
$\mathrm{O}-\mathrm{Fe}-\mathrm{F}, \circ$ & 175.6 & 174.5 \\
$\Delta d\left(\mathrm{Fe}-\mathrm{N}_{4}\right), \AA$ & 0.073 & 0.098 \\
\hline
\end{tabular}




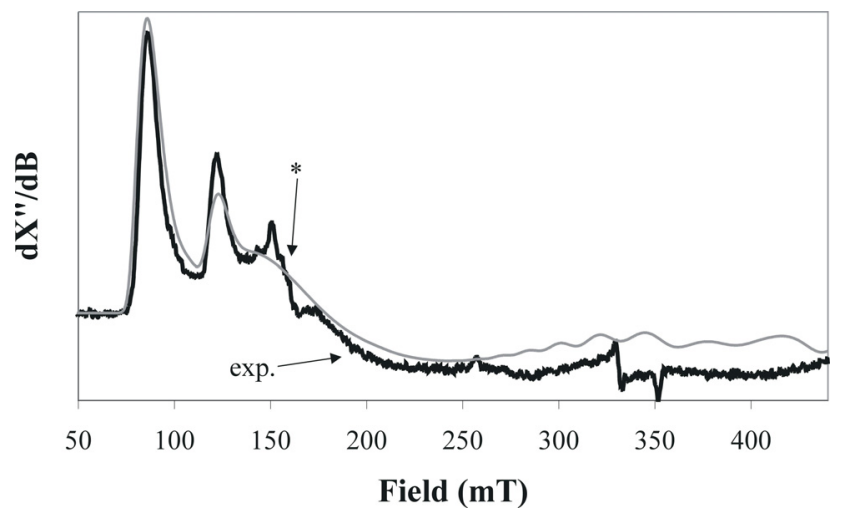

Figure S1. X-Band EPR spectrum of 1 taken in frozen BuCN solution at $10 \mathrm{~K}$. The solid grey line is an $S=5 / 2$ spin Hamiltonian simulation of the data with the parameters $D=-4 \mathrm{~cm}^{-1}, E / D=0.10$, with a Gaussian distribution of $E / D$ having $\sigma(E / D)$ $=0.034$. The asterisk denotes a minor "shit-iron" impurity at $g_{\text {eff }}=4.3$. 


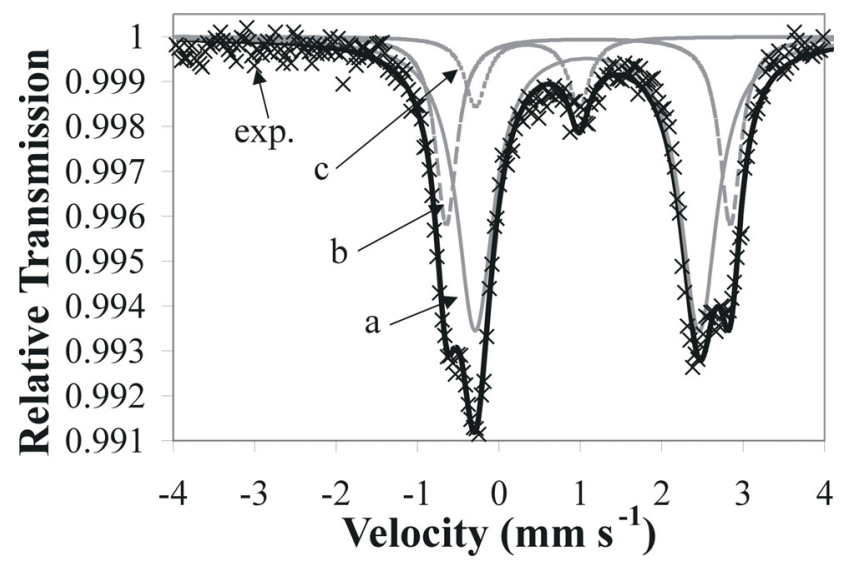

Figure S2. Mössbauer spectrum of a solution of 1 in acetonitrile with $0.1 \mathrm{M} \mathrm{NBu}_{4} \mathrm{PF}_{6}$ after coulometric reduction at $-0.4 \mathrm{~V}$ [1 red]. The solid line is the sum of the three subspectra a, b, and c which have Mössbauer parameters $\delta \mathrm{a}=1.08 \mathrm{~mm} \mathrm{~s}^{-1}, \Delta \mathrm{E}_{\mathrm{Q}} \mathrm{a}=$ $2.75 \mathrm{~mm} \mathrm{~s}^{-1} ; \delta \mathrm{b}=1.10 \mathrm{~mm} \mathrm{~s}^{-1}, \Delta \mathrm{E}_{\mathrm{Q}} \mathrm{b}=3.49 \mathrm{~mm} \mathrm{~s}^{-1} ; \delta \mathrm{c}=0.35 \mathrm{~mm} \mathrm{~s}^{-1}, \Delta \mathrm{E}_{\mathrm{Q}} \mathrm{c}=1.27 \mathrm{~mm}$ $\mathrm{s}^{-1}$. Species a and $\mathrm{b}$ are both high-spin iron(II) species and $\mathrm{c}$ is a high-spin iron(III) species (perhaps having a $\mu$-oxo group), and the relative percentages of the three species are: $a=66 \%, b=25 \%, c=9 \%$. 


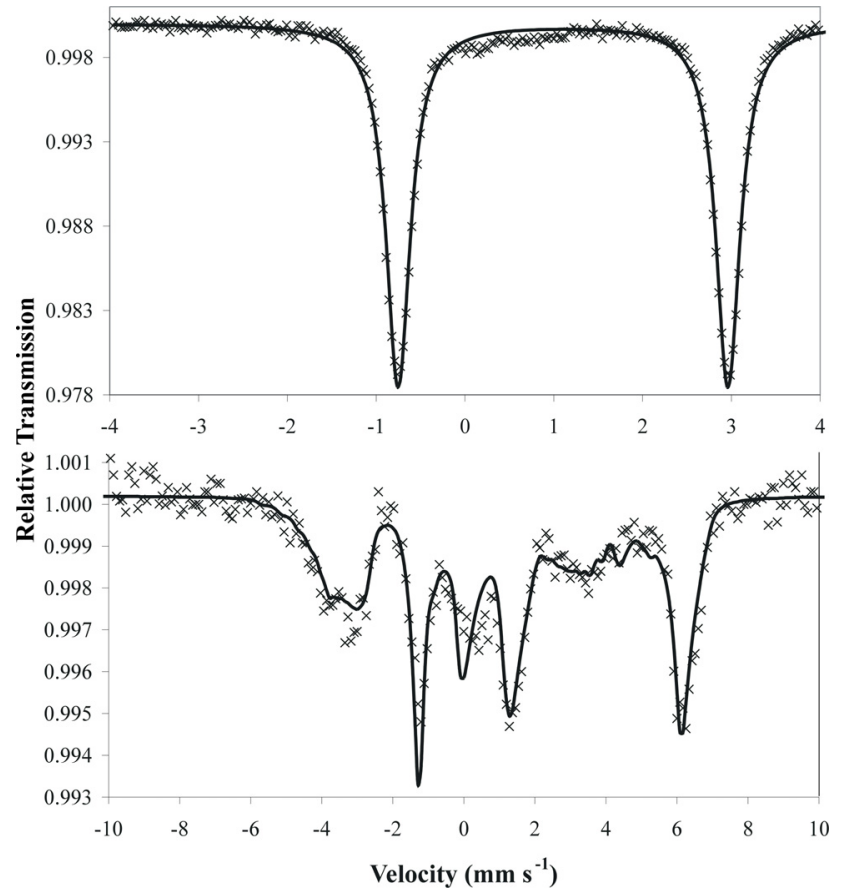

Figure S3. Mössbauer spectrum of 2red at $80 \mathrm{~K}$ (top) and at $4.2 \mathrm{~K}$ and in an applied magnetic field of $7 \mathrm{~T}$ (bottom). The solid line in the bottom spectrum is the result of a spin-Hamiltonian simulation with the parameters given in Table 2. 


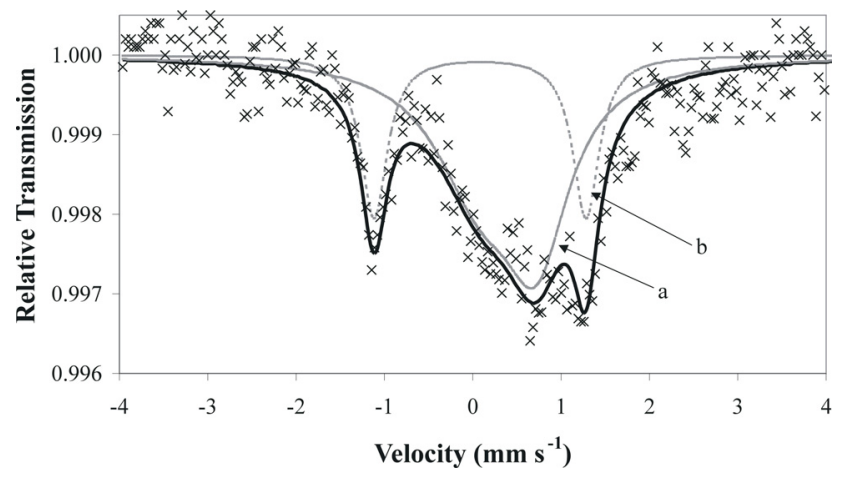

Figure S4. Mössbauer spectrum of an acetonitrile solution of 1 with $0.1 \mathrm{M} \mathrm{NBu}_{4} \mathrm{PF}_{6}$ after coulometric oxidation of $<50 \%$ of the sample. Subspectrum a corresponds to a high spin ferric species which is most likely unoxidized $\mathbf{1}$ and was fitted with the following parameters: $\delta=0.40 \mathrm{~mm} \mathrm{~s}^{-1}, \Delta \mathrm{E}_{\mathrm{Q}}=0.64 \mathrm{~mm} \mathrm{~s}^{-1}, \Gamma=0.90 \mathrm{~mm} \mathrm{~s}^{-1}, \mathrm{w} \_\mathrm{R} / \mathrm{L}=$ $1.375, \mathrm{I} \_\mathrm{R} / \mathrm{L}=0.937$, relative intensity $=70.9 \%$. Subspectrum $\mathrm{b}$ has the following parameters $\delta=0.08 \mathrm{~mm} \mathrm{~s}^{-1}, \Delta \mathrm{E}_{\mathrm{Q}}=2.40 \mathrm{~mm} \mathrm{~s}^{-1}, \Gamma=0.36 \mathrm{~mm} \mathrm{~s}^{-1}$. 